\title{
Minimally Invasive Locoregional Treatment of Intrahepatic Cholangiocellular Carcinoma
}

\author{
Daniel Putzer, Peter Schullian, Werner R. Jaschke, Reto Bale
}

Interventional Oncology - Microinvasive Therapy (SIP), Department of Radiology, Medical University of Innsbruck, Austria

\section{ABSTRACT}

\author{
Corresponding author: \\ Reto Bale, MD \\ Interventional Oncology - Microinvasive \\ Therapy (SIP), Department of Radiology \\ Medical University of Innsbruck \\ Anichstr.35, 6020 Innsbruck, Austria \\ E-mail: reto.bale@i-med.ac.at
}

Surgical resection is considered first-line treatment for intrahepatic cholangiocellular carcinoma (ICC). In case of a unresectable tumor, chemotherapy is part of standardized treatment guidelines, despite dismal outcome. Technical advances in locoregional therapies such as radiofrequency ablation, microwave ablation, irreversible electroporation, transarterial chemoembolization and selective internal radiation therapy bear the promise for enhancing local tumor control, while reducing treatment associated morbidity and improving survival as well asquality of life. This review focuses on the latest improvements of minimally invasive locoregional therapies and their implementation in modern multimodality treatment protocols for ICC.

Key words: radiofrequency ablation, cholangiocarcinoma, hepatic liver tumor treatment, thermal ablation

\section{INTRODUCTION}

Cholangiocarcinomas arise from the epithelial cells of bile ducts, forming intrahepatic or extrahepatic neoplasms, and are the second most common primary liver malignancy, accounting for 10 to $15 \%$ of liver malignancies diagnosed worldwide $(1,2)$. Approximately 5 to $10 \%$ of cholangiocarcinomas are intrahepatic (3).

Intrahepatic cholangiocellular carcinomas (ICCS) can originate from either small intrahepatic ductules (peripheral ICCs) or large intrahepatic ducts proximal to the bifurcation of the right and left hepatic ducts. ICC tumor growth patterns include the mass-forming type, the periductal-infiltrating type with associated intrahepatic ductal dilation, and a mixed type. The purely mass-forming type is most common, accounting for approximately $60 \%$ of all ICCS, whereas the purely periductal and mixed types account for approximately $20 \%$ of cases each (4).

ICCs are frequently diagnosed in an advanced stage of disease. They progress rapidly and lead to biliary obstruction and liver failure. Surgery is the established standard treatment approach (5). Resectability rates for ICCs have increased over time, due in part to more aggressive operative strategies and
Received: 02.09.2018

Accepted: 07.10.2018 
broadened criteria for resectability (6). However, the majority of cases recur despite potentially curative RO resection (7-13), leading to a reccurrence rate of up to $70 \%$ (14). The median overall survival after surgical resection is 18 to 30 months (15). One third of patients are still unresectable (16).

Kolarich performed a retrospective analysis of the treatment strategies in 6140 patients with ICC diagnosed in the United States between 2004 and 2015. Only $29 \%$ of these patients were surgical candidates, and in the subgroup of the remaining patients with stage I disease RFA was the only treatment strategy with improved survival (17). Orthotopic liver transplantation (OLT) is not considered to be a standard therapeutic approach for localized cholangiocarcinoma (18).

To date, no prospective trials are available about the value of adjuvant external beam radiation therapy after local curative resection, and results from retrospective studies are contradictory.

Chemotherapy and radiation therapy did not succeed in significantly increasing the long term survival in unresectable patients. The preferred chemotherapeutic regimen consists of a combination of gemcitabine and cisplatin and results in a median progression-free survival (PFS) of 8 months and a median overall survival (OS) of 12 months (19). Studies evaluating this combination reported a survival benefit of 8 months over gemcitabine monotherapy $(20,21)$. However, current guidelines indicate that radiotherapy and selective internal radiation therapy (SIRT) may be considered as second line treatments after chemotherapy (22).

In this article we review current strategies of minimally invasive locoregional treatment of ICC.

\section{MINIMAL INVASIVE LOCOREGIONAL TREATMENT APPROACHES}

\section{Transarterial therapies}

Transarterial embolisation (TAE), transarterial chemoembolisation (TACE) and SIRT are highly selective treatment options for ICC. For TACE combines a mixture of lipiodol and chemotherapeutic agents such as doxorubicin, gemcitabine, mitomycin or epirubicin. Drug eluting bead TACE (DEB-TACE) uses embolizing beads that are loaded with chemotherapeutic agents.

DEB-TACE results in similar overall survival as compared to conventional TACE. Whether TAE or TACE is superior has not yet been shown in randomized, controlled trials (23). TACE has led to prolonged survival (12.2. months) in 155 patients suffering from unresectable ICC in comparison to best supportive care (3.3 months)(24). In 2013, a metaanalysis of hepatic artery-based therapies for unresectable ICC found a median overal survival of 15.7 months from diagnosis and 13.4 months from therapy (25). TACE in combination with systemic therapies has shown to prolong survival. In a systematic review, including 13 studies with 504 ICC patients undergoing TAE therapies using chemotherapeutic agents or radiation, the progressionfree survival ranged from 1.8 to 10 months, and the $1-, 2$ - and 3- year survival rates were $38-78 \%, 12-38 \%$ and $4-30 \%(26)$.

Transarterial selective internal radiotherapy (SIRT) is performed using Yttrium-90 glass or resin microspheres. The effect of mechanical embolization is combined with the delivery of biologically highly effective ß-radiation at the tumor site. Results of SIRT in ICC have been summarized in a review, reporting a median survival time ranging from 4.4 to 52 months (27). A systematic review of SIRT in ICC reported a partial response in $28 \%$ and stable diesease in $54 \% 3$ months postinterventionally, summarizing 12 studies (28).

In a study including 198 patients with ICC undergoing treatment with chemoembolization, bland embolization, or radioembolization, complete or partial radiographic responses in 41 patients were reported, while 99 had stable disease. The median overall survival was 13.2 months and did not differ according to the type of intraarterial therapy (29).

\section{Local ablative treatment}

Ablative procedures include radiofrequency ablation (RFA), microwave ablation (MWA), cryotherapy and irreversible electroporation (IRE). In 2002, the first case of RFA in ICC was published by Slakey et al., combining ablation and surgery in recurrent disease after liver surgery (30). Case reports confirming these first finding followed in the following years (31-33). In 2012, Bale and coworkers reported on the advantage of stereotactic RFA, allowing precise multiplanar planning of RFA even in large sized tumors. A median overall survival of 60 months was reached, making stereotactic RFA an alternative to resection (34).

In recurrent ICC, multifocal tumor and restricted liver function are immanent clinical problems requiring safe and technically advanced treatment options (35).

RFA is a well established local treatment option based on high frequency alternating current, that can be performed under local anasthesia or general anesthesia. Contraindications for RFA include central bile duct invasion, biliodigestive anastomosis and 
clinically relevant coagulation disorders. Probes are placed under computed tomography (CT)-, ultrasound (US)-, or magnetic resonance tomography (MRI) guidance. Local tissue heating of up to $100^{\circ}$ is achieved in the tissue adjacent to the non-isolated part of the probe, leading to coagulation necrosis. Needle placement and ablation duration are at the discretion of the performing radiologist, such that the ablation zone covers the tumor with a safety margin of at least $1 \mathrm{~cm}$ or greater.

Complete ablation of the tumor is confirmed in the control imaging at the end of the intervention, allowing for reinsertion and repeat ablation, if necessary. Histopathologic studies have confirmed that local curative treatment can be reached by RFA if an ablation margin of $1 \mathrm{~cm}$ of healthy tissue surrounding the tumor is achieved (34).

Follow up imaging after local treatment includes CT and MRI 3 to 6 months postinterventionally or according to clinical needs during the postoperative period. Evaluation of images is performed to standardized criteria following ablation (36).

RFA combines a highly effective treatment approach with favorable results, with low morbidity and mortality rates (table 1). A non-controlled metaanalysis including 3670 patients reported a complication rate of $8.9 \%$ and a mortality rate of $0.5 \%$ (37). However, the technical approach to RFA varies widely, leading to heterogeneous results in technical success and tumor reccurrence rate after RFA. US guided RFA has shown to be feasible in tumors smaller than $3 \mathrm{~cm}$. However, in tumors larger than $3 \mathrm{~cm}, 3$ out of 7 tumors could not be ablated completely (38). These results are not equal to reports on RFA using conventional CT guidance for needle placement. A progression free survival of 32.3. months and a median survial of 38.5 months was reached, with 1-, 3- and 5- year survival rates of 85,51 and $15 \%(39,40)$.

Microwave ablation (MWA) is based on creation of an electromagnetic field creating heat in the tumor tissue. It has also shown to be an effective local treatment approach in ICC patients, with a technical success rate of $91.7 \%$ (41). Takahashi et al published data on 20 patients with 50 ICCs, who were treated using RFA or MWA between 2006 and 2015, including patients with recurrence of disease after surgery. No significant difference was observed in outcome of RFA and MWA treatment. No major complication occurred. The estimated 1-, 3- and 5-year survival rates were $95 \%, 40 \%$ and $0.32 \%$. Five patients suffered local tumor progression after ablation, with a median time to progression of 7.1 months (42).

Similar reports included 18 and 26 patients, respectively, comparing RFA to MWA alone or MWA in combination with TACE $(43,44)$. Another study group reported a median overall survival in 105 patients with ICC following RFA and a combination of treatments in a retrospective chart review of 16.1 months (45). Kim et al. reported a longer median overall survival in a group of 20 patients following RFA of ICC with 38.5 months (46), which was confirmed by findings of Fu et al. (47).

Zhang et al. compared survival rates in patients with reccurrent ICCs after hepatic resection or thermoablative treatment, and did not find a significant

Table 1 - Case control studies reporting results of thermal ablation in primary or recurrent ICC

\begin{tabular}{|c|c|c|c|c|c|}
\hline Author (Ref.) & $\begin{array}{c}\text { Thermal ablation } \\
\text { technique }\end{array}$ & $\begin{array}{c}\text { Year of } \\
\text { publication }\end{array}$ & $\begin{array}{c}\text { Number of } \\
\text { patients }\end{array}$ & $\begin{array}{c}\text { Number of } \\
\text { tumors and size }\end{array}$ & $\begin{array}{c}\text { Mean overal surviva } \\
\text { (months) }\end{array}$ \\
\hline Bale (59) & SRFA & 2013 & 17 & $\begin{array}{c}52 \\
\text { up to } 10 \mathrm{~cm}\end{array}$ & 60 \\
\hline Takahashi (42) & RFA, MWA & 2018 & 20 & $\begin{array}{c}50 \\
1.8 \pm 1.3 \mathrm{~cm}\end{array}$ & 23.6 \\
\hline Zhang (48) & RFA, MWA & 2013 & 109 & $\begin{array}{c}177 \\
\text { up to } 6.7 \mathrm{~cm}\end{array}$ & 21.3 \\
\hline Carafiello (39) & RFA & 2010 & 6 & $\begin{array}{c}6 \\
1 \text { to } 5.8 \mathrm{~cm}\end{array}$ & 20 \\
\hline $\operatorname{Kim}(40)$ & RFA & 2011 & 13 & $\begin{array}{c}17 \\
\text { up to } 5 \mathrm{~cm}\end{array}$ & 38.5 \\
\hline Giorgio (57) & RFA & 2011 & 10 & 2.5 to $3.2 \mathrm{~cm}$ & $\begin{array}{c}\text { Follow-up of only } \\
19.5 \text { months }\end{array}$ \\
\hline Butros (3) & RFA & 2014 & 7 & $\begin{array}{c}9 \\
1.3 \text { up to } 3.3 \mathrm{~cm}\end{array}$ & 38.5 \\
\hline Fu (47) & RFA & 2011 & 12 & $\begin{array}{c}19 \\
1.9 \text { up to } 6.8 \mathrm{~cm}\end{array}$ & 30 \\
\hline
\end{tabular}


difference in tumors with a size below $3 \mathrm{~cm}$. The 1-, 2and 3- year overall survival rates were 69.8, 37.3 and $20.5 \%$ for RFA patients, with no significant difference to patients undergoing surgery (48). Kamphues et al. reported a series of 13 patients undergoing liver resection in combination with RFA of ICC, and found both approaches to be safe and effective, with an overall survival of 51 months (49).

The pooled 1-, 3- and 5- year overall survival rates reported in a metaanalysis including 7 studies for outcome of RFA in ICCs are $82 \%, 47 \%$ and $24 \%$. RFA prolonged survival even in unresectable ICC patients. However, technical success rates varied between 88 and $100 \%$ and technical effectiveness rates varied between 66 and $96.2 \%$. Major complication rates were low, between 0 and $8.3 \%$ (50). Possible complications of RFA include hepatic failure, bleeding, liver abscess, pneumothorax, bowel perforation. A study comparing liver resection to RFA in ICC reported a higher rate of major complications after surgery than in the RFA group, with $46.9 \%$ vs. $3.9 \%$ (48).

\section{Stereotactic radiofrequency ablation}

Stereotactic Radiofrequency Ablation (SRFA) combines the advantages of local ablative treatment and precise needle placement using a 3D- planning software, patient immobilisation devices, aiming devices, tube disconnection during needle placement and muscular blockade.

It facilitates a multiple needle approach and precise tumor ablation even in unresectable tumors. It allows for precise placement of multiple probes, creating overlapping coagulation necrosis. In contrast to conventional ultrasound and CT guided single probe ablation, SRFA allows for effective treatment of large ICCS (51-57).

The 3D navigation system is used to visualize the needle position in real time in relation to preoperatively aquired CT, MRI, SPECT or PET image data sets. The needle pathways can be adopted accordingly.The size of the necrosis depends on the distribution of heat from the electrode tip to the periphery of the tumor, as well as on the blood flow at the site of ablation, leading to the so called heat sink effect. This effect can be overcome by increased duration and power of ablation, with ablation probes being preferentially positioned in the region of the tumor next to the vessel site. Needle placement is performed with high accuracy. A median lateral error of needle placement of $2.5 \mathrm{~mm}$ was reported (58). Haidu et al. reported a 1- and 3- year survival rate of $91 \%$ and $71 \%$ in 11 patients after SRFA (34), with an estimated median overall survial of 60 months. Tumor size did not influence overall survival. No patient died perioperatively and the morbidity rate was $13.8 \%(59)$.

\section{Irreversible electroporation}

Irreversible electroporation (IRE) is a non-thermal image-guided ablation technique based on creating short-pulsed high- voltage current fields, inducing cellular apoptosis. The electrical pulses permeabilise the lipid bilayer of the cell membrane, hereby disrupting intracellular homeostasis and inducing apoptosis.

Due to the non-thermal mechanism, the method is causing less damage to surrounding tissue, especially when probes are positioned next to bile ducts, hereby overcoming limitations of the before mentioned ablation techniques. The number of probes used for ablation depends on tumour size and shape. A recently published metaanalysis on treatment of hepatic malignant tumors with IRE reported a significant reduction in tumor diameter, but no survival data is available so far (60).

\section{Cryoablation}

Despite the fact that cryoablation represents a valuable tool in thermal ablation therapies, no study group has yet investigated the role in treatment of cholangiocellular carcinoma, yet. In cryoablation, specific ablation probes are applied, using argon or helium gas to freeze tissue, creating an ice ball predefined by the given probe. The treatment effect can be directly monitorized by visualization of the ice ball. A variety of cryoablation probes is available, in order to create the appropriate ice ball necessary to cover the tumor target. Nevertheless, the first studies on cryoablation reported a significant number of adverse events in comparison to other thermal ablation techniques (61). In addition, the technical issue on needle tract ablation has not been solved yet for cryoablation probes, increasing the risk of tumor seeding.

\section{OUTLOOK}

Despite surgery being listed as the standard treatment approach for ICC, this rare and aggressive liver neoplasm is often managed non-surgically, as local ablative techniques are currently improving, enabling local tumor control in combination with low morbidity and mortality rates. Especially in patients suffering a more advanced stage of disease and liver function 
restriction, or in elderly patients, feasible and effective local treatment approaches have the potential to improve survival and quality of life. Although multiple therapeutic approaches are available for locoregional therapy of ICC, prospective randomized controlled trials for treatment effectiveness are not yet available. Controlled case series and metaanalyses are available for local ablative therapies and TACE. Heterogeneous patient populations and inconsistent therapeutic regimens hamper a comparison of available data. RFA is a safe and highly effective treatment option, resulting in a potential survival benefit and improving the quality of life of ICC patients in comparison to chemotherapy or best supportive care. Due to its minimal invasiveness and at least equal local control rates to surgical resection multiprobe stereotactic RFA challenges surgery as first line treatment in ICC.

\section{CONCLUSION}

Minimally invasive thermal ablation methods represent potentially local curative treatment approaches for ICCs. RFA offers a safe and oncologic feasible alternative to surgery, being associated with a significantly lower complication rate and less loss of liver parenchyma as compared to hepatic resection. In contrast to conventional ultrasound- and CT- guided RFA, multiprobe stereotactic RFA allows for treatment of more complex and larger liver tumors, by using 3D navigation systems and image registration techniques. Future trials should focus on a combination of locoregional ablation techniques and systemic treatment for possible improvement in survival. The future holds the promise of more complex multimodal treatment concepts for CCA patients to improve overall survival and quality of life.

\section{Conflict of interest}

\section{All author declare that they have no conflict of} interest.

\section{REFERENCES}

1. Khan SA, Taylor-Robinson SD, Toledano MB, Beck A, Elliott P, Thomas HC. Changing international trends inmortality rates for liver, biliary and pancreatic tumours. J Hepatol.2002;37(6):806-13.

2. Shaib Y, El-Serag HB. The epidemiology of cholangiocarcinoma. Semin Liver Dis. 2004;24(2):115-25.

3. Butros SR, Shenoy-Bhangle A, Mueller PR, Arellano RS. Radiofrequency ablation of intrahepatic cholangiocarcinoma: feasability, local tumor control, and long-term outcome. Clin Imaging. 2014; 38(4):490-494.

4. Banales J, Cardinale V, Carpino G, Marzioni M, Andersen JB, Invernizzi Pet al. Expert consensus document: cholangiocarcinoma: current knowledge and future perspectives consensus statement from the European Network for the Study of Cholangiocarcinoma (ENS-CCA). Nat. Rev. Gastroenterol. Hepatol. 2016;13(5), 261-280.

5. Simo KA, Halpin LE, McBrier NM,Hessey JA, Baker E, Roos S et al. Multimodality treatment of intrahepatic cholangiocarcinoma: a review. Journal ofSurgical Oncology. 2016;113(1):62-83.

6. Khan SA, Davidson BR, Goldin RD, Heaton N, Karani J, Pereira SP, et al. Guidelines for the diagnosis and treatment of cholangiocarcinoma: an update. Gut.2012;61(12):1657-69.

7. Poultsides GA, Zhu AX, Choti MA, Pawlik TM. Intrahepatic cholangiocarcinoma. SurgClin North Am 2010; 90:817.

8. Maithel SK, Gamblin TC, Kamel I, Corona-Villalobos CP, Thomas M, Pawlik TM. Multidisciplinary approaches to intrahepatic cholangio carcinoma. Cancer 2013; 119:3929.

9. Mavros MN, Economopoulos KP, Alexiou VG, Pawlik TM. Treatment and Prognosis for Patients With Intrahepatic Cholangiocarcinoma: Systematic Review and Meta-analysis. JAMA Surg 2014;149:565.

10. Spolverato G, Vitale A, Cucchetti A, Popescu I, Marques HP, Aldrigheetti $L$ et al. Can hepatic resection provide a long-term cure for patients with intrahepatic cholangiocarcinoma? Cancer 2015; 121:3998.

11. DeOliveira ML, Cunningham SC, Cameron JL, Kamangar F, Winter $\mathrm{JM}$, Lillemoe KD et al. Cholangiocarcinoma: thirty-one-year experience with 564 patients at a single institution. Ann Surg 2007; $245: 755$.

12. Paik KY, Jung JC, Heo JS, Choi SH, Kim YI. What prognostic factors are important for resected intrahepatic cholangiocarcinoma? J GastroenterolHepatol 2008; 23:766.

13. Lang H, Sotiropoulos GC, Sgourakis G, Schmitz KJ, Paul A, Hilgard $P$ et al. Operations for intrahepatic cholangiocarcinoma: singleinstitution experience of 158 patients. J Am CollSurg 2009; 208(2): 218-228.

14. Park HM, Yun SP, Lee EC, Lee SD, Han SS, Kim SH et al. Outcomes for patients with recurrent intrahepatic cholangiocarcinoma after surgery. Ann Surg0ncol; 2016;23(13):4392-4400.

15. Coelen R, Vogel JA,Vroomen LGPH,Roos E,Busch ORC et al. Ablation with irreversible electroporation in patients with advanced perihilar cholangiocarcinoma (ALPACA): a multicentre phase I/II feasibility study protocol. BMJ Open.2017;7(9):e015810.

16. Braunwarth E, Stättner S, Fodor M, Cardini B, Resch T, Oberhuber R, et al. Surgical techniques and strategies for the treatment of primary liver tumours: hepatocellular and cholangiocellular carcinoma. Eur Surg. 2018;50:100-112.

17. Kolarich A, Shah JL, George Jr TJ, Hughes SJ, Shaw CM, Geller BS et al. Non-surgical management of patients with intrahepatic cholangiocarcinoma in the United States, 2004-2015: an NCDB analysis. J Gastrointest Oncol.2018;9(3):536-545.

18. DeOliveira ML, Liver Transplantation for cholangiocarcinoma: current best practice. CurrOpin Organ Transplant.2014;19(3):245-252.

19. Valle J, Wasan H, Palmer DH, Cunningham D. Anhoney A, Maraveyas A et al. Cisplatin plus gemcitabine versus gemcitabine for biliary tract Cancer. N Engl J Med 2010;362:1273-81.

20. Eckel F, Schmid RM. Chemotherapy and targeted therapy in advanced biliary tract carcinoma: a pooled analysis of clinical trials. Chemotherapy 2014;60:13-23.

21. Valle J, Wasan H, Palmer DH, Cunningham D, Anthoney $A$, Maraveyas A, et al. Cisplatin plus gemcitabine versus gemcitabine for biliary tract cancer. N Engl J Med. 2010;362(14):1273-81.

22. Koay EJ, Odisio BC, Javle M, Vauthey J-N, Crane CH. Management of unresectable intrahepatic cholangiocarcinoma: how do we decide among the various liver-directed treatments? Hepatobiliary Surg Nutr. 2017;6(2):105-116.

23. Ierardi A, Angileri S, Patella F, Panella S, Lucchian N, Petre EN et al. The role of interventional radiology in the treatment of intrahepatic cholangiocarcinoma. Med. Oncol.2017;34(1),11.

24. Park SY, Kim JH, Yoon HJ, Lee IS, Yoon HK, Kim KP. Transarterial chemoembolization versus supportive therapy in the palliative treat- ment of unresectable intrahepatic cholangiocarcinoma. Clin Radiol. 2011;66:322-8.

25. Ray CE Jr, Edwards A, Smith MT, Leong S, Kondo K, Gipson M, et al. Metaanalysis of survival, complications, and imaging response 
following chemotherapy-based transarterial therapy in patients with unresectable intrahepatic cholangiocarcinoma. J Vasc Interv Radiol. 2013;24(8):1218-26.

26. Yang L, Shan J, Shan L, Saxena A, Bester L, Morris DL. Transarterial embolisation therapies for unresectable intrahepatic cholangiocarcinoma: a systematic review. J Gastrointest Oncol. 2015;6:570-588.

27. Mosconi C, Cappelli A, Ascanio S, Pettinari I, Modestino F, Renzull $\mathrm{M}$, et al. Yttrium-90 microsphere radioembolization in unresectable intrahepatic cholangiocarcinoma. Future Oncol. 2017;13(15):13011310.

28. Al-Adra D, Gill RS, Axford SJ, Shi X, Kneteman N, Liau SS Treatment of unresectable intrahepatic cholangiocarcinoma with yttrium-90 radioembolization: a systematic review and pooled analysis. Eur J Surg Oncol. 2015;41(1),120-127.

29. Hyder O, Marhs W, Salem R, Petre EN, Kalva S, Liapi E et al. Intraarterial Therapy for Advanced Intrahepatic Cholangiocarcinoma: A Multiinstitutional Analysis. Annals of Surgical Oncology. 2013; 20(12):3779-3786.

30. Slakey DP. Radiofrequency ablation of recurrent cholangiocarcinoma. Am Surg. 2002;68:395-397.

31. Genov I, Grigorov N, Mitova R, Golemanov B, Dinkov L. Radiofrequency ablation of recurrent intrahepatic cholangiocarcinoma: a case report. Khirurgiia (Sofiia). 2005;45-7.

32. Rai R, Manas D, Rose J. Radiofrequency ablation of recurrent cholangiocarcinoma after orthotopic liver transplantation - a case report. World J Gastroenterol. 2005;11:612-3.

33. Oshima S, Takaishi K, Kurokawa E. A case of successful management of recurrent intrahepatic cholangiocarcinoma by repeated radiofrequency ablations. Gan To Kagaku Ryoho.2009;36:2404-6.

34. Haidu M, Dobrozemsky G, Schullian P, Widmann G, Klaus A, Weiss $\mathrm{H}$ et al. Stereotactic radiofrequency ablation of unresectable intrahepatic cholangiocarcinomas: a retrospective study. Cardiovasc Intervent Radiol. 2012;35(5):1074-82.

35. Sommer CM, Kauczor HU, Pereira PL, Locoregional Therapies of Cholangiocarcinoma. Visc Med. 2016;32(6):414-420.

36. Ahmed M, Solbiati L, Brace CL, Breen DJ, Callstrom MR, Charboneau JW, et al. Image-guided tumor ablation: standardization of terminology and reporting criteria - a 10-year update. Radiology. 2014;273(1):241-60

37. Mulier S, Ni Y, Jamart J, Ruers T, Marchal G, Michel L. Local recurrence after hepatic radiofrequency coagulation: multivariate metaanalysis and review of contributing factors. Ann Surg. 2005; 242(2):158-71.

38. Chiou YY, Hwang Jl, Chou YH, Wang HK, Chiang JH, Chang CY Percutaneous ultrasound-guided radiofrequency ablation of intrahepatic cholangiocarcinoma. Kaohsiung J Med Sci. 2005;21(7): 304-9.

39. Carrafiello G, Laganà D, Cotta E, Mangini M, Fontana F, Bandiera F, et al. Radiofrequency ablation of intrahepatic cholangiocarcinoma preliminary experience. Cardiovasc Intervent Radiol. 2010;33(4): 835-9.

40. Kim JH, Won HJ, Shin YM, Kim KA, Kim PN. Radiofrequency ablation for the treatment of primary intrahepatic cholangiocarcinoma. AJR Am J Roentgenol. 2011;196(2):W205-9.

41. Yu MA, Liang P, Yu XL, Cheng ZG, Han ZY, Liu FY, et al. Sonographyguided percutaneous microwave ablation of intrahepatic primary cholangiocarcinoma. Eur J Radiol. 2011:80(2):548-52.

42. Takahashi EA, Kinsman KA, Schmit GD, Atwell TD, Schmitz JJ, Welch BT et al. Thermal ablation of intrahepatic cholangiocarcinoma: Safety, efficacy, and factors affecting local tumor progression. AbdomRadiol (2018) https://doi.org/10.1007/s00261-018-1656-3.
43. Xu H, Wang Y, Lu M, Liu L. Percutaneous ultrasound-guided thermal ablation for intrahepatic cholangiocarcinoma. Br. J. Radiol. 2012;85(1016):1078-1084.

44. Yang GW, Zhao Q, Qian S, Zhu L, Qu XD, Zhang W, et al. Percutaneous microwave ablation combined with simultaneous transarterial chemoembolization for the treatment of advanced intrahepatic cholangiocarcinoma. Onco Targets Ther. 2015;8:1245-50.

45. Dhanasekaran R, Hemming AW, Zendejas I, George T, Nelson DR, Soldevila-Pico C, et al. Treatment outcomes and prognostic factors of intrahepatic cholangiocarcinoma. Oncol Rep. 2013;29(4):1259-67.

46. Kim JH, Won HJ, Shin YM, Kim PN, Lee SG, Hwang S. Radiofrequency ablation for recurrent intrahepatic cholangiocarcinoma after curative resection. Eur J Radiol. 2011;80(3):e221-5.

47. Fu Y, Yang W, Wu W, Yan K, Xing BC, Chen MH. Radiofrequency ablation for postoperative recurrences of intrahepatic cholangiocarcinoma. Chin J Cancer Res. 2011;23(4):295-300.

48. Zhang SJ, Hu P, Wang N, Shen Q, Sun A, Kuang M et al.Thermal ablation versus repeated hepatic resection for recurrent intrahepatic cholangiocarcinoma. Ann Surg Oncol. 2013; 20(11):3596-602.

49. Kamphues C, Seehofer D, Eisele RM, Denecke T, Pratschke J, Neumann UP, et al. Recurrent intrahepatic cholangiocarcinoma: single-center experience using repeated hepatectomy and radiofrequency ablation. J Hepatobiliary Pancreat Sci. 2010;17(4):509-15.

50. Han K, Ko HK, Kim KW, Won HJ, Shin YM, Kim PN. Radiofrequency ablation in the treatment of unresectable intrahepatic cholangiocarcinoma: systematic review and meta-analysis. J Vasc Interv Radiol. 2015;26(7):943-8.

51. Bale R, Widmann G, Jaschke W. Stereotaxy and robotics for ablation - toy or tool? Radiologe. 2012;52(1):56-62.

52. Bale R, Widmann G, Jaschke W. Navigated open, laparoscopic, and percutaneous liver surgery. Minerva Chir. 2011;66(5):435-53.

53. Bale R, Widmann G, Schullian P, Haidu M, Pall G, Klaus A, Weiss H, Biebl M, Margreiter R. Percutaneous stereotactic radiofrequency ablation of colorectal liver metastases. EurRadiol. 2012;22(4): 930-7.

54. Widmann G, Schullian P, Haidu M, Bale R. Stereotactic radiofrequency ablation (SRFA) of liver lesions: technique effectiveness, safety, and interoperator performance. Cardiovasc Intervent Radiol. 2012;35(3): 570-80.

55. Bale R, Widmann G, Haidu M. Stereotactic radiofrequency ablation. Cardiovasc Intervent Radiol. 2011;34(4):852-6.

56. Chiou YY, Hwang Jl, Chou YH, Wang HK, Chiang JH, Chang CY. Percutaneous ultrasound-guided radiofrequency ablation of intrahepatic cholangiocarcinoma. Kaohsiung J MedSci. 2005; 21:304-9.

57. Giorgio A, Calisti G, DE Stefano G, Farella N, DI Sarno A, Amendola F, et al. Radiofrequency ablation for intrahepatic cholangiocarcinoma: retrospective analysis of a single centre experience. Anticancer Res. 2011:31(12):4575-80.

58. Schullian P, Widmann G, Lang TB, Knoflach M, Bale R. Accuracy and diagnostic yield of CT-guided stereotactic liver biopsy of primary and secondary liver tumors. Comput Aided Surg. 2011;16(4):181-7.

59. Bale R, Schullian P, Haidu M, Widmann G. Stereotaktische Radiofrequenzablation von intrahepatischen cholangiozellulären Karzinomen - eine minimal invasive Alternative zur Leberresektion. Wien Med Wochenschr.2013:163:128-131.

60. Tian G, Zhao Q, Chen F, Jiang T, Wang W. Ablation of hepatic malignant tumors with irreversible electroporation: a systematic review and meta-analysis of outcomes. Oncotarget 2017;8(4), 5853-5860.

61. Pearson AS, Izzo F, Fleming RY, Ellis LM, Delrio P, Roh MS, et al. Intraoperative radiofrequency ablation or cryoablation for hepatic malignancies. Am J Surg1999;178:592-599. 